\title{
Secretion of A-type and B-type natriuretic peptides into the bloodstream and pericardial space in children with congenital heart disease
}

Yoshio Ootaki, MD, PhD

Masahiro Yamaguchi, MD, PhD

Naoki Yoshimura, MD, PhD

Shigeteru Oka, MD, PhD

Masahiro Yoshida, MD

Tomomi Hasegawa, MD

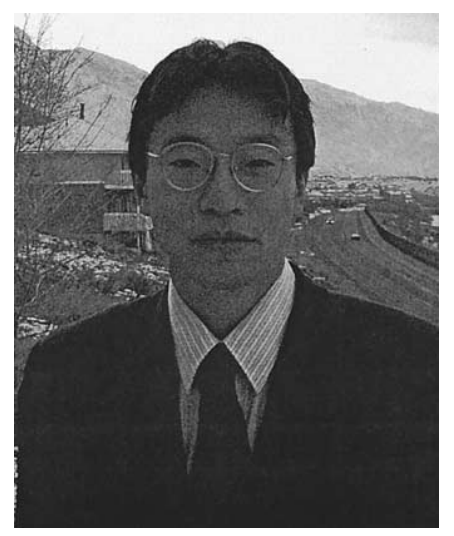

Dr Ootaki
From the Department of Cardiothoracic Surgery, Kobe Children's Hospital, Kobe, Hyogo, Japan.

Received for publication Nov 7, 2002; revisions requested Dec 30, 2002; revisions received March 17, 2003; accepted for publication April 11, 2003.

Address for reprints: Dr Yoshio Ootaki, 1-1-1 Takakuradai, Suma-ku, Kobe, Hyogo 654-0081, Japan (E-mail: y.ootaki@nifty. ne.jp).

J Thorac Cardiovasc Surg 2003;126:1411-6 Copyright (C) 2003 by The American Association for Thoracic Surgery

0022-5223/2003\$30.00+0

doi:10.1016/S0022-5223(03)01020-1
Objective: To determine the secretion of A-type and B-type natriuretic peptides into the bloodstream and pericardial space in children with congenital heart disease.

Methods: Plasma and pericardial fluid samples were obtained from 77 patients undergoing total correction for congenital heart disease. All patients underwent detailed right-sided and left-sided cardiac catheterization preoperatively.

Results: A-type natriuretic peptide levels in pericardial fluid were lower than those in plasma $(33.0 \pm 23.1$ versus $39.8 \pm 33.6 \mathrm{pg} / \mathrm{mL}, P<.05)$, and B-type natriuretic peptide levels in pericardial fluid showed marked elevations compared with those in plasma $(231.9 \pm 305.6$ versus $19.8 \pm 29.3 \mathrm{pg} / \mathrm{mL}, P<.0001)$. The A-type and B-type natriuretic peptide levels in plasma correlated with those in pericardial fluid $(R=.522, P<.0001 ; R=.595, P<.0001)$. For A-type and B-type natriuretic peptide levels in plasma, the relation with biventricular volume had the highest correlation $(R=.669, P<.0001 ; R=.652, P<.0001)$. The patients with a pulmonary-to-systemic flow ratio greater than $2(\mathrm{n}=19)$ had high levels of natriuretic peptides not only in plasma $(58.3 \pm 43.2,40.5 \pm 49.4 \mathrm{pg} / \mathrm{mL}, P<.05)$ but also in pericardial fluid $(44.4 \pm 31.5,287.2 \pm 198.5 \mathrm{pg} / \mathrm{mL}, P<.05)$, and higher correlation between A-type and B-type natriuretic peptide plasma levels and left ventricular volume $(R=.913, P<.0001 ; R=.787, P<.0001)$.

Conclusions: B-type natriuretic peptide is secreted not only into the bloodstream but also into the pericardial space in children with congenital heart disease. Natriuretic peptide levels in plasma correlated well with biventricular volume. The left ventricle was considered to be the main source of secreted natriuretic peptides in the patients with a pulmonary-to-systemic flow ratio greater than 2 .

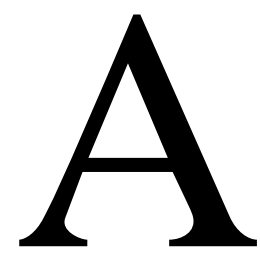

-type (atrial) and B-type (brain) natriuretic peptides (ANP and BNP) are circulating peptides produced principally by the atria and ventricles, respectively. ${ }^{1,2}$ Both peptides increase sodium and water excretion, suppress renin and aldosterone secretion, and lead to venous and arterial dilatation. ${ }^{3}$ They may also favorably influence autonomic function and have direct and indirect antimitotic effects in the heart and blood vessels. ${ }^{4}$ It was believed that most of the ANP and BNP was secreted into the bloodstream and acted as a systemic hormone. ANP and BNP have also been reported to have local autocrine and paracrine functions at the site of their synthesis ${ }^{5,6}$ and to be secreted into the pericardial space. ${ }^{7}$ Now, ANP and BNP play an important part in the diagnosis of chronic heart failure (CHF), ${ }^{8}$ predict late-term survival, ${ }^{9}$ and are used to treat CHF. ${ }^{10,11}$ Although many reports 
TABLE 1. Main diagnosis in 77 patients

\begin{tabular}{lc}
\hline Main diagnosis & Number \\
\hline Ventricular septal defect & 16 \\
+ Pulmonary hypertension & 6 \\
$\quad+$ Pulmonary artery banding & 8 \\
Atrial septal defect & 14 \\
Tetralogy of Fallot & 12 \\
Single ventricle & 6 \\
Pulmonary atresia & 5 \\
Double-outlet right ventricle & 4 \\
Atrioventricular septal defect with pulmonary artery & 4 \\
$\quad$ banding & \\
Transpositions of great arteries & 1 \\
Double-chambered right ventricle & 1 \\
\hline
\end{tabular}

have examined plasma ANP and BNP concentrations in adults with CHF, few have explored the natriuretic peptide concentrations in children with congenital heart disease (CHD). ${ }^{12-14}$ Furthermore, the secretion of ANP and BNP as a component of the pericardial fluid (PF) into the pericardial space in CHD is still unknown. The purposes of this study were to determine (1) whether ANP and BNP are secreted into the pericardial space in children with CHD, (2) whether the levels of ANP and BNP correlate with the severity of the disease, and (3) whether the levels of ANP and BNP differ in some diseases.

\section{Patients and Methods}

The study was approved by the local institutional review board and all parents gave written informed consent. The study was comprised of 77 children, aged 3 months to 14 years, undergoing elective preoperative cardiac catheterization before the surgery for definitive repair of the congenital cardiac malformation. Informed consent was obtained from each participating patient. The main cardiac diagnoses are listed in Table 1 . The children were divided into 3 groups: group 1, those with a pulmonary-to-systemic flow ratio less than 1; group 2, those with a pulmonary-to-systemic flow ratio 1 to 2 ; group 3 , those with a pulmonary-to-systemic flow ratio greater than 2. Thirty-two of 77 patients had total of 40 previous operations or catheter interventions. The type and number of operations or interventions were 14 pulmonary artery bandings, 18 Blalock-Taussig shunts, 2 aortopulmonary shunts, 1 repair of total pulmonary venous drainage, and 5 balloon pulmonary valvuloplasties.

All patients underwent right-sided and left-sided cardiac catheterizations. Left atrial pressure was obtained by direct measurement or by measuring the average of the bilateral pulmonary capillary wedge pressure. Right and left ventricular volumes were calculated from biplane cineangiograms. Right ventricular volumes were calculated using Simpson's rule method, and left ventricular volumes were calculated by the area-length method. Right ventricular end-diastolic volume (RVEDV) and left ventricular end-diastolic volume (LVEDV) were corrected for body surface area (BSA) and were expressed RVEDV index (RVEDVI) and LVEDV index (LVEDVI). RVEDV and LVEDV were also ex-
TABLE 2. Hemodynamic and hormonal data

\begin{tabular}{|c|c|c|c|}
\hline & $\begin{array}{l}\text { Group } 1 \\
(n=18)\end{array}$ & $\begin{array}{l}\text { Group 2 } \\
(\mathrm{n}=40)\end{array}$ & $\begin{array}{l}\text { Group } 3 \\
(n=19)\end{array}$ \\
\hline Age (y) & $5.3 \pm 2.4$ & $6.2 \pm 3.0$ & $6.3 \pm 3.9$ \\
\hline Weight (kg) & $16.5 \pm 8.6$ & $21.3 \pm 13.0$ & $20.9 \pm 11.6$ \\
\hline MRAP $(\mathrm{mm} \mathrm{Hg})$ & $3.8 \pm 1.3$ & $3.9 \pm 2.1$ & $3.7 \pm 2.2$ \\
\hline SRVP $(\mathrm{mm} \mathrm{Hg})$ & $96.9 \pm 13.4$ & $64.3 \pm 30.3 \dagger$ & $52.6 \pm 23.1 \dagger$ \\
\hline $\operatorname{MLAP}(\mathrm{mm} \mathrm{Hg})$ & $6.0 \pm 3.5$ & $7.0 \pm 2.6$ & $6.8 \pm 3.9$ \\
\hline LVEDP (mm Hg) & $8.2 \pm 1.2$ & $9.8 \pm 3.6$ & $8.7 \pm 4.2$ \\
\hline Op/0s & $0.74 \pm 0.28$ & $1.37 \pm 0.29 *$ & $2.86 \pm 1.58^{*} \dagger$ \\
\hline RVESVI $\left(\mathrm{mL} / \mathrm{m}^{2}\right)$ & $23.9 \pm 11.8$ & $30.2 \pm 9.6$ & $35.6 \pm 8.1^{*}$ \\
\hline RVEDVI $\left(\mathrm{mL} / \mathrm{m}^{2}\right)$ & $69.3 \pm 26.5$ & $76.7 \pm 24.3$ & $91.0 \pm 20.8^{*}$ \\
\hline RVEF $(\%)$ & $64.6 \pm 9.4$ & $60.1 \pm 8.5$ & $64.5 \pm 19.2$ \\
\hline LVESVI $\left(\mathrm{mL} / \mathrm{m}^{2}\right)$ & $22.0 \pm 5.7$ & $26.0 \pm 11.4$ & $25.9 \pm 17.3$ \\
\hline LVEDVI $\left(\mathrm{mL} / \mathrm{m}^{2}\right)$ & $65.8 \pm 16.5$ & $81.4 \pm 29.8$ & $78.4 \pm 37.2$ \\
\hline LVEF (\%) & $66.4 \pm 7.1$ & $67.9 \pm 7.8$ & $67.8 \pm 9.2$ \\
\hline RV\%Normal (\%) & $116.5 \pm 39.6$ & $121.6 \pm 36.7$ & $148.2 \pm 36.2^{*} \dagger$ \\
\hline LV\%Normal (\%) & $116.1 \pm 27.7$ & $135.9 \pm 57.0$ & $139.1 \pm 85.5$ \\
\hline TV\%Normal (\%) & $226.2 \pm 26.1$ & $248.0 \pm 62.0$ & $280.0 \pm 99.0$ \\
\hline $\begin{array}{l}\text { ANP in plasma (pg/ } \\
\mathrm{mL})\end{array}$ & $29.5 \pm 23.5$ & $35.7 \pm 29.5$ & $58.3 \pm 43.2^{*} \dagger$ \\
\hline $\begin{array}{l}\text { BNP in plasma (pg/ } \\
\mathrm{mL})\end{array}$ & $10.4 \pm 9.7$ & $14.2 \pm 15.0$ & $40.5 \pm 49.4^{*} \dagger$ \\
\hline ANP in $P F(p g / m L)$ & $30.1 \pm 13.5$ & $27.9 \pm 18.7$ & $44.4 \pm 31.5 \dagger$ \\
\hline BNP in $P F(p g / m L)$ & $121.1 \pm 21.0$ & $159.6 \pm 25.7$ & $287.2 \pm 198.5^{*} \dagger$ \\
\hline
\end{tabular}

The children were divided into 3 groups: group 1, those with a pulmonaryto-systemic flow ratio less than 1 ; group 2 , those with a pulmonary-tosystemic flow ratio 1 to 2; group 3; those with a pulmonary-to-systemic flow ratio greater than 2 .

$M R A P$, Mean atrial pressure; SRVP, systolic right ventricular pressure; $M L A P$, mean left atrial pressure; $L V E D P$, left ventricular end-diastolic pressure; $Q p / Q s$, pulmonary flow to systemic flow ratio; RVESVI, right ventricular end-systolic volume index; RVEDVI, right ventricular end-diastolic volume index; $R V E F$, right ventricular ejection fraction; $L V E S V I$, left ventricular end-systolic volume index; LVEDVI, left ventricular end-diastolic volume index; $L V E F$, left ventricular ejection fraction; $A N P, A$-type natriuretic peptide; $B N P$, B-type natriuretic peptide; $P F$, pericardial fluid. Data are expressed as mean value \pm SD.

${ }^{*} P<.05$ vs. group 1.

$\dagger P<.05$ vs. Group 2.

pressed as a percentage of the predicted normal values using the formula derived by Nakazawa and colleagues. ${ }^{15}$

$$
\begin{aligned}
& \text { Predicted normal RVEDV }(\mathrm{mL})=75.1 \times \operatorname{BSA}\left(\mathrm{m}^{2}\right)^{1.43} \\
& \text { Predicted normal LVEDV }(\mathrm{mL})=72.5 \times \operatorname{BSA}\left(\mathrm{m}^{2}\right)^{1.43}
\end{aligned}
$$

RV\%Normal (\%) and LV\%Normal (\%) were expressed as a percentage of the predicted normal RVEDV and LVEDV. TV(total volume)\%Normal (\%) was calculated by adding RV\%Normal and LV\% Normal.

The definitive repair for congenital heart defects was performed in all patients within 3 months after the cardiac catheterization. All patients with a single ventricle underwent total cavopulmonary connection. Plasma ANP and BNP concentrations were withdrawn from the cannulated brachial artery after induction of anesthesia and before skin incision. Undiluted samples of pericardial fluid were obtained immediately after the incision of the pericardium. Each blood specimen was collected in a chilled tube containing 4.5 

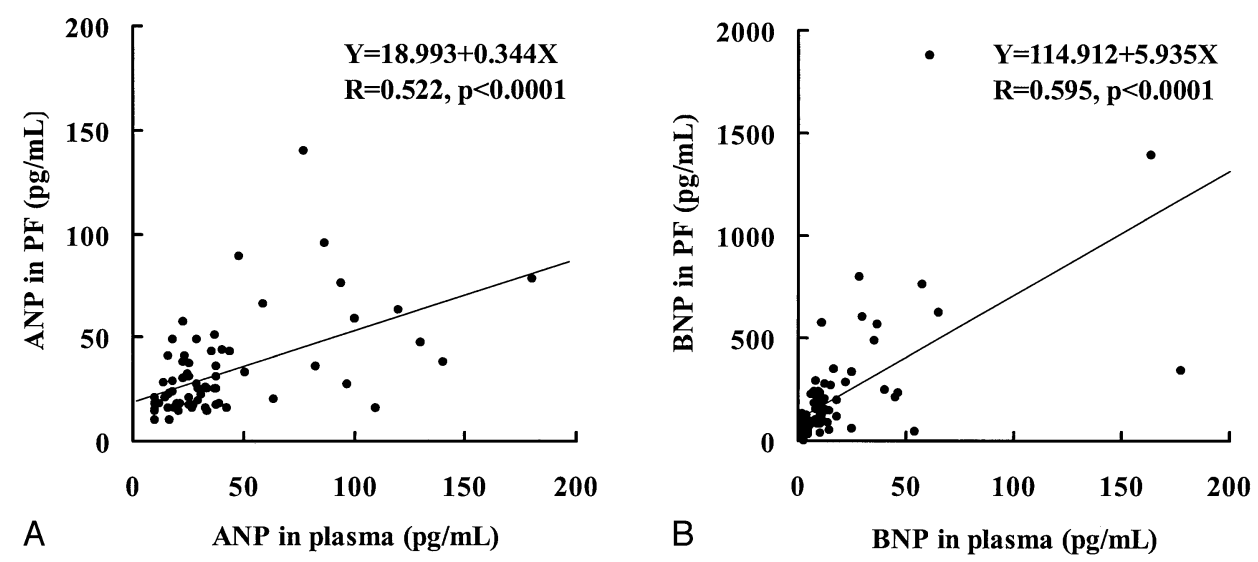

Figure 1. $A$ and $B$, The relations between natriuretic peptide levels in plasma and those in PF.

$\mathrm{mg}$ of sodium ethylenediaminetetraacetic acid and 1500 units of aprotinin. The pericardial fluid was collected in sterile tubes. Each sample was placed immediately on ice, separated by centrifugation at $3000 \mathrm{~g}$ for 10 minutes at $4^{\circ} \mathrm{C}$ and rapidly frozen at $-80^{\circ} \mathrm{C}$ until a hormone assay was performed. Concentrations of ANP and BNP in the plasma and pericardial fluid were measured by a commercially available specific radioimmunoassay system (SRL Inc, Tokyo, Japan). The concentrations of ANP and BNP were expressed in picograms per milliliter, and their normal ranges were less than $40 \mathrm{pg} / \mathrm{mL}$ and $20 \mathrm{pg} / \mathrm{mL}$, respectively.

All values were expressed as mean \pm standard deviation. An unpaired Student $t$ test and 1-way repeated-measures analysis of variance were used to assess the differences in hemodynamic and hormonal data. When the differences were determined by the 1-way repeated-measures analysis of variance to be significant, the differences were further analyzed by the Scheffé test. Differences were considered significant at $P<.05$. The correlations between differences in natriuretic peptide levels of plasma and hemodynamic, hormonal variables were calculated by linear regression analysis.

\section{Results}

ANP levels in PF were less than those in plasma (33.0 \pm 23.1 versus $39.8 \pm 33.6 \mathrm{pg} / \mathrm{mL}, P<.05)$, and BNP levels in PF showed marked elevations compared with those in plasma $(231.9 \pm 305.6$ versus $19.8 \pm 29.3 \mathrm{pg} / \mathrm{mL}, P<$ $.0001)$. Figure 1, $A$ and $B$ show the relationships between natriuretic peptide levels in plasma and those in PF. The ANP and BNP levels in plasma correlated with those in PF ( $R=.522, P<.0001 ; R=.595, P<.0001$, respectively).

Hemodynamic and hormonal data in each group are listed in Table 2. The patients in group 3 had the highest levels of ANP and BNP levels not only in the plasma (58.3 $\pm 43.2,40.5 \pm 49.4 \mathrm{pg} / \mathrm{mL})$ but also in the PF $(44.4 \pm 31.5$, $287.2 \pm 198.5 \mathrm{pg} / \mathrm{mL})$.

The correlation coefficients for the relation between each of the independent variables and natriuretic peptide levels from 2 sampling sites in all patients are listed in Table 3, and those in each group are listed in Tables 4, 5, and 6. For ANP and BNP plasma levels in all patients, the relation with
TV\%Normal had the highest correlation (Figure 2, $A$ and $B$ ) ( $R=.669, P<.0001 ; R=.652, P<.0001$, respectively). For ANP and BNP plasma levels, the relation with RV\% Normal had a tendency of higher correlation in group $1(R=.655, P=.0032 ; R=.523, P=.0260$, respectively $)$ and group $2(R=.642, P<.0001 ; R=.613, P<.0001$, respectively) compared with $\mathrm{LV} \%$ Normal, while the relation with LV\% Normal had higher correlation in group $3(R$ $=.913, P<.0001 ; R=.787, P<.0001$, respectively) compared with RV\%Normal.

\section{Discussion}

ANP and BNP are released mainly from atrial and ventricular myocytes, respectively. Most of the ANP and BNP were believed to be secreted into the bloodstream and act as a systemic hormone. However, a recent study reported that natriuretic peptides are secreted from the heart into the pericardial space in response to left ventricular dysfunction, ${ }^{7}$ and they might have a pathophysiologic role in heart failure as an autocrine and paracrine factor. ${ }^{5,6}$ Klemola and colleagues $^{16}$ also reported that a previous anterior myocardial infarction was associated with increased cardiac BNP production even if the left ventricular systolic function was normal.

The present study demonstrated that BNP levels in PF showed marked elevations compared with those in plasma, and ANP levels in PF were lower than those in plasma. The BNP level in PF was 5.9-fold higher when compared with the BNP level in plasma. Tanaka and associates ${ }^{7}$ reported that the ANP level in PF was 8.9-fold and BNP level 27-fold higher when compared with the ANP and BNP levels in plasma. Klemola and associates ${ }^{16}$ also reported that the ANP level in PF was 2.5-fold and BNP level 4.2-fold higher when compared with the ANP and BNP levels in plasma. Our results of $\mathrm{BNP}$ in $\mathrm{PF}$ are similar to these results. However, BNP levels in plasma and PF of our patient did not reach as a high level as Tanaka and colleagues reported. ${ }^{7}$ That may be because that the patients in Tanaka and 
TABLE 3. Linear regression analyses of association between hemodynamic variables and ANP and BNP levels in plasma and PF (all patients: $\mathbf{n}=77$ )

\begin{tabular}{|c|c|c|c|c|c|c|c|c|}
\hline & \multicolumn{2}{|c|}{ ANP in plasma } & \multicolumn{2}{|c|}{ BNP in plasma } & \multicolumn{2}{|c|}{ ANP in PF } & \multicolumn{2}{|c|}{ BNP in PF } \\
\hline & Coefficient & $P$ value & Coefficient & $P$ value & Coefficient & $P$ value & Coefficient & $P$ value \\
\hline Op/Os & .4860 & $<.0001$ & .3800 & .5354 & .1420 & .2646 & .3080 & .0133 \\
\hline RVESVI & .1580 & .1810 & .2200 & .6190 & .2500 & .0430 & .3420 & .0049 \\
\hline RVEDVI & .0082 & .4920 & .1240 & .2962 & .2280 & .0659 & .3270 & .0074 \\
\hline RVEF & .1140 & .3309 & .0830 & .4800 & .0280 & .8215 & .1430 & .2535 \\
\hline LVESVI & .4860 & $<.0001$ & .5750 & $<.0001$ & .2320 & .0630 & .1430 & .2535 \\
\hline LVEDVI & .4760 & $<.0001$ & .5020 & $<.0001$ & .1700 & .1762 & .1370 & .2762 \\
\hline LVEF & .1300 & .2708 & .1810 & .1219 & .1510 & .2296 & .0940 & .4566 \\
\hline RV\%Normal & .3710 & .0011 & .3200 & .0055 & .4090 & .0007 & .4600 & .0001 \\
\hline LV\%Normal & .6250 & $<.0001$ & .5750 & $<.0001$ & .2680 & .0308 & .2030 & .1044 \\
\hline TV\%Normal & .6690 & $<.0001$ & .6520 & $<.0001$ & .3340 & .0054 & .4190 & .0004 \\
\hline
\end{tabular}

See Table 2 for abbreviations.

TABLE 4. Linear regression analyses of association between hemodynamic variables and ANP and BNP levels in plasma and PF (group 1: $\mathbf{n = 1 8}$ )

\begin{tabular}{|c|c|c|c|c|c|c|c|c|}
\hline & \multicolumn{2}{|c|}{ ANP in plasma } & \multicolumn{2}{|c|}{ BNP in plasma } & \multicolumn{2}{|c|}{ ANP in PF } & \multicolumn{2}{|c|}{ BNP in PF } \\
\hline & Coefficient & $P$ value & Coefficient & $P$ value & Coefficient & $P$ value & Coefficient & $P$ value \\
\hline Op/Os & .6130 & .0089 & .6910 & .0021 & .0200 & .9493 & .1720 & .5744 \\
\hline RVESVI & .5240 & .0257 & .4000 & .1003 & .5750 & .0314 & .3220 & .2609 \\
\hline RVEDVI & .7470 & .0004 & .5760 & .0124 & .6460 & .0125 & .0630 & .8295 \\
\hline RVEF & .3780 & .1219 & .2940 & .2364 & .0260 & .9303 & .5630 & .0361 \\
\hline LVESVI & .0840 & .7496 & .3220 & .2075 & .3450 & .2476 & .3260 & .2763 \\
\hline LVEDVI & .0800 & .7608 & .3580 & .1587 & .6520 & .0158 & .2240 & .4610 \\
\hline LVEF & .1120 & .6682 & .0870 & .7393 & .1560 & .6103 & .2310 & .4471 \\
\hline RV\%Normal & .6550 & .0032 & .5230 & .0260 & .4610 & .0970 & .1490 & .6109 \\
\hline LV\%Normal & .4440 & .0740 & .6330 & .0064 & .1140 & .7102 & .3910 & .1864 \\
\hline TV\%Normal & .3290 & .1827 & .2290 & .3605 & .3780 & .1823 & .3300 & .2497 \\
\hline
\end{tabular}

See Table 2 for abbreviations.

TABLE 5. Linear regression analyses of association between hemodynamic variables and ANP and BNP levels in plasma and PF (group 2: $n=40$ )

\begin{tabular}{|c|c|c|c|c|c|c|c|c|}
\hline & \multicolumn{2}{|c|}{ ANP in plasma } & \multicolumn{2}{|c|}{ BNP in plasma } & \multicolumn{2}{|c|}{ ANP in PF } & \multicolumn{2}{|c|}{ BNP in PF } \\
\hline & Coefficient & $P$ value & Coefficient & $P$ value & Coefficient & $P$ value & Coefficient & $P$ value \\
\hline $0 p / 0 s$ & .0230 & .8923 & .0520 & .7616 & .0020 & .9918 & .0920 & .6165 \\
\hline RVESVI & .3600 & .0285 & .4010 & .0139 & .5900 & .0003 & .7160 & $<.0001$ \\
\hline RVEDVI & .3700 & .0240 & .4200 & .0096 & .4730 & .0054 & .5980 & .0002 \\
\hline RVEF & .0670 & .6887 & .0800 & .6323 & .1850 & .3017 & .1710 & .3407 \\
\hline LVESVI & .2120 & .2022 & .1350 & .4177 & .3870 & .0237 & .1870 & .2903 \\
\hline LVEDVI & .2710 & .0999 & .2730 & .0976 & .4850 & .0036 & .3200 & .0649 \\
\hline LVEF & .0350 & .8322 & .1490 & .3668 & .0940 & .5957 & .1630 & .3573 \\
\hline RV\%Normal & .6420 & $<.0001$ & .6130 & $<.0001$ & .6530 & $<.0001$ & .7250 & $<.0001$ \\
\hline LV\%Normal & .4050 & .0105 & .3290 & .0410 & .5670 & .0005 & .3520 & .0409 \\
\hline TV\%Normal & .5870 & $<.0001$ & .5720 & .0001 & .4810 & .0034 & .5850 & .0002 \\
\hline
\end{tabular}

See Table 2 for abbreviations.

colleagues' study included many heart failure patients who had high BNP/ANP ratio in plasma. Conversely, the plasma BNP/ANP ratio is reversed in CHF in our study. Bolger and associates ${ }^{17}$ also reported that the plasma concentration of
BNP was lower than that of ANP in adults with CHD. These results may suggest that the degree of heart failure was mild in our patients with CHD or that there were some differences in the mechanism of BNP secretion between CHD in 

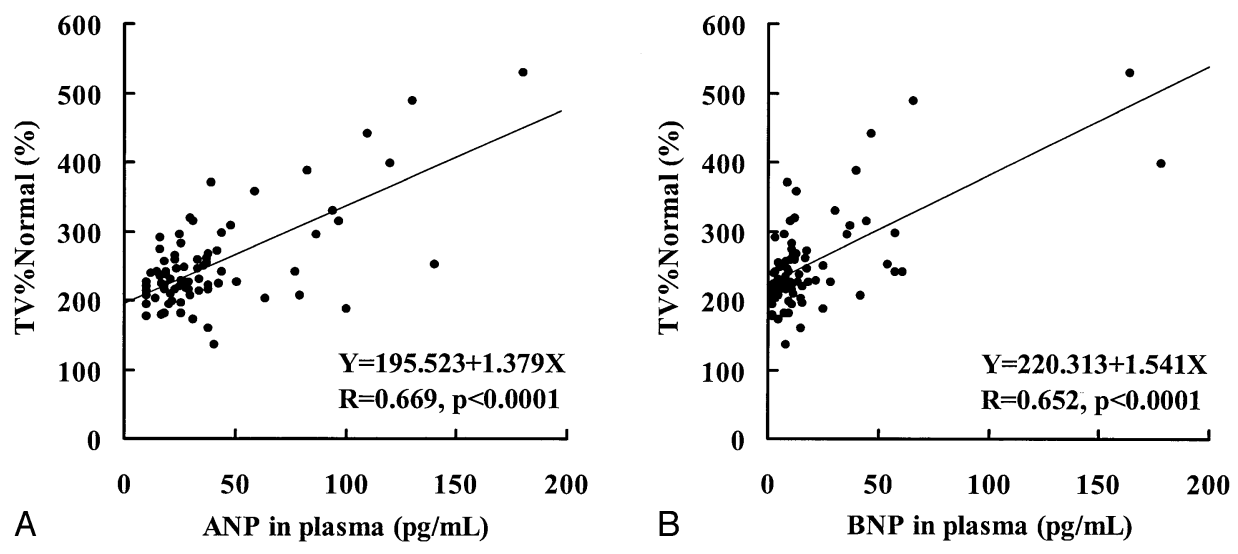

Figure 2. $A$ and $B$, The relations between natriuretic peptide levels in plasma and TV\%Normal.

TABLE 6. Linear regression analyses of association between hemodynamic variables and ANP and BNP levels in plasma and PF (group 3: $n=19$ )

\begin{tabular}{|c|c|c|c|c|c|c|c|c|}
\hline & \multicolumn{2}{|c|}{ ANP in plasma } & \multicolumn{2}{|c|}{ BNP in plasma } & \multicolumn{2}{|c|}{ ANP in PF } & \multicolumn{2}{|c|}{ BNP in PF } \\
\hline & Coefficient & $P$ value & Coefficient & $P$ value & Coefficient & $P$ value & Coefficient & $P$ value \\
\hline Qp/0s & .4230 & .0710 & .1410 & .5649 & .1370 & .5750 & .0060 & .9818 \\
\hline RVESVI & .2130 & .3815 & .0360 & .8841 & .2220 & .3606 & .1960 & .4219 \\
\hline RVEDVI & .3780 & .1107 & .2780 & .2500 & .1700 & .4866 & .1460 & .5505 \\
\hline RVEF & .2370 & .3277 & .1860 & .4453 & .0170 & .9449 & .1560 & .5230 \\
\hline LVESVI & .8530 & $<.0001$ & .9010 & $<.0001$ & .1940 & .4401 & .2150 & .3927 \\
\hline LVEDVI & .8570 & $<.0001$ & .7980 & $<.0001$ & .0190 & .9415 & .0600 & .8120 \\
\hline LVEF & .4040 & .0960 & .5020 & .0338 & .4430 & .0655 & .3430 & .1635 \\
\hline RV\%Normal & .1320 & .5902 & .0850 & .7291 & .3780 & .1104 & .3630 & .1262 \\
\hline LV\%Normal & .9130 & $<.0001$ & .7870 & .0001 & .0610 & .8105 & .1390 & .5825 \\
\hline TV\%Normal & .8420 & $<.0001$ & .7340 & .0003 & 1900 & .4354 & .2920 & .2259 \\
\hline
\end{tabular}

See Table 2 for abbreviations.

children and ischemic heart disease in adults. Ischemia or infarction of cardiomyocytes may play an important role in elevating BNP levels in PF.

On the other hand, our results of ANP in PF did not indicate high levels when compared with the BNP in PF. Yasue and associates ${ }^{2}$ reported that the ANP levels in a coronary sinus showed marked elevation (15.5-fold) compared with levels in the aortic root, whereas the BNP levels in the coronary sinus only showed more than 4 times the levels in the aortic root. The differences of natriuretic peptide level in PF suggest that BNP is secreted predominantly into the pericardial space rather than into the bloodstream or that BNP has a longer half-life in the pericardial fluid than in plasma. Maack and associates ${ }^{18}$ reported that the circulating ANP and BNP were cleared by their clearance receptor. Suga and associates ${ }^{19}$ reported that the affinity of the clearance receptor (C-receptor) of ANP, which is expressed in a wide variety of tissues, was higher than that of BNP. This effect may be responsible partially for the marked elevation of the BNP in PF.
In adult patients, left ventricular end-systolic volume index (LVESVI) or left end-diastolic volume index (LVEDVI) has a significant relationship with ANP or BNP levels in plasma. ${ }^{2}$ However, our results demonstrated the highest relationships between natriuretic peptides and TV\%Normal. It is important to note that LVEDV/BSA or RVEDV/BSA should not be used for normalization of enddiastolic volumes for patient size because the relationships between EDV and BSA were neither linear nor proportional in normal children, thus the ratio of EDV/BSA will change with BSA and show erroneous differences when comparing groups of different mean age. Furthermore, many hearts with CHD have a diseased right ventricle. It is essential to estimate not only the diseased left ventricle but also the diseased right ventricle in considering the secretion of natriuretic peptides.

As we did not measure the ANP levels in the coronary sinus or anterior interventricular vein, it was unknown whether increased amounts of ANP were secreted from the atrium or the ventricle. Both ANP and BNP in plasma 
exhibited high correlation with TV\%Normal, not with the atrial pressure of the right and left atrium. These results suggest that ANP may be secreted to the bloodstream not only from the atrium but also the ventricle in these dilated ventricles with CHD.

The present study demonstrated that the secretions of natriuretic peptides were different in each group of congenital heart disease. The patients with a pulmonary-to-systemic flow ratio greater than 2 had higher ANP and BNP levels in plasma and higher correlation between ANP and BNP plasma levels and left ventricular volume, while the patients with a pulmonary-to-flow ratio less than 2 had lower ANP and BNP levels in plasma and higher correlation between ANP and BNP plasma levels and right ventricular volume. The present study did not demonstrate whether the natriuretic hormone was highly secreted from a left ventricle or a right ventricle. However, the high correlation between natriuretic hormone and the left ventricle suggests that the left ventricle was the main source of secreted natriuretic peptides.

An obvious limitation of our study is the number of patients. Activation of neurohormonal systems in children with CHD has been described, but the broader relevance of these individual findings to CHD populations as a whole has been difficult to gauge because common clinical denominators have been difficult to apply to this anatomically heterogeneous population. Further studies in a larger number of patients (particularly those with cyanotic heart disease and ventricular septal defect with pulmonary hypertension) are needed to clarify the contribution of each factor to the levels of ANP and BNP in plasma and PF. The second limitation of this study is a lack of normal children as a control. The normal range of natriuretic peptides in children had already been reported by Yoshibayashi and associates in $1995 .^{20}$ They reported that the ANP and BNP levels in healthy children were the highest at 0 days of age and decreased through maturation to be almost constant at the adult level at 3 months of age. In this study group, the normal range of the ANP and BNP levels was considered to be the same as the adult level, expressed in femtomole per milliliter. Although the assay and units of natriuretic peptide levels are different between Yoshibayashi and colleagues' study and our study, the value of natriuretic peptides expressed in femtomole per milliliter can be calculated, as the molecular weights of ANP and BNP are known to be 3080.5 and 3464.1. Therefore, the normal range of specific radioimmunoassay system in adults as less than $40 \mathrm{pg} / \mathrm{mL}$ and 20 $\mathrm{pg} / \mathrm{mL}$, respectively, will be applicable to the normal range in children. However, the normal range of the ANP and BNP levels in PF in normal children is still unclear.

In summary, BNP is secreted not only into the bloodstream but also into the pericardial space in children with CHD. Natriuretic peptides levels in plasma correlated well with biventricular volume. The patients with a pulmonaryto-systemic flow ratio greater than 2 had higher correlation between ANP and BNP plasma levels and left ventricular volume. These results suggest that the left ventricle was the main source of secreted natriuretic peptides.

We thank Mr. Michael Kopcak for editorial advice.

\section{References}

1. Yoshimura M, Yasue H, Okumura K, et al. Different secretion patterns of atrial natriuretic peptide and brain natriuretic peptide in patients with congestive heart failure. Circulation. 1993;87:464-9.

2. Yasue H, Yoshimura M, Sumida $H$, et al. Localization and mechanism of secretion of B-type natriuretic peptide in comparison with those of A-type natriuretic peptide in normal subjects and patients with heart failure. Circulation. 1994;90:195-203.

3. Needleman P, Greenwald JE. Atriopeptin: a cardiac hormone intimately involved in fluid, electrolyte, and blood-pressure homeostasis. N Engl J Med. 1986;314:828-34.

4. Chen HH, Burnett JC Jr. The natriuretic peptides in heart failure: diagnostic and therapeutic potentials. Proc Assoc Am Physicians. 1999;111:406-16.

5. Cao L, Gardner DG. Natriuretic peptides inhibit DNA synthesis in cardiac fibroblasts. Hypertension. 1995;25:227-34.

6. Lin X, Hanze J, Heese F, Sodmann R, Lang RE. Gene expression of natriuretic peptide receptors in myocardial cells. Circ Res. 1995;77:750-8.

7. Tanaka T, Hasegawa K, Fujita M, et al. Marked elevation of brain natriuretic peptide levels in pericardial fluid is closely associated with left ventricular dysfunction. J Am Coll Cardiol. 1998;31:399-403.

8. Lubien EL, DeMaria A, Krishnaswamy P, et al. Utility of B-natriuretic peptide in detecting diastolic dysfunction: comparisons with Doppler velocity recordings. Circulation. 2002;105:595-601.

9. McCullough PA, Nowak RM, McCord J, et al. B-type natriuretic peptide and clinical judgment in emergency diagnosis of heart failure: analysis from breathing not properly (BNP) multinational study. Circulation. 2002;106:416-22.

10. Mizuno O, Onishi K, Dohi K, et al. Effects of therapeutic doses of human atrial natriuretic peptide on load and myocardial performance in patients with congestive heart failure. Am J Cardiol. 2001;88:863-6.

11. Colucci WS, Elkayam U, Horton DP, et al. Intravenous nesiritide, a natriuretic peptide, in the treatment of decompensated congestive heart failure. Nesiritide Study Group. N Engl J Med. 2000;343:246-53.

12. Holmstork H, Thaulow E, Stokke O, Lindberg H, Hall C. Serum $\mathrm{N}$-terminal proatrial natriuretic factor in children with congenital heart disease. Eur Heart J. 1996;17:1737-46.

13. Takaya J, Ikemoto Y, Teraguchi M, Nogi S, Kobayashi Y. Plasma nitric oxide products correlate with cardiac index of congenital heart disease. Pediatr Cardiol. 2000;21:378-81.

14. Yoshimura N, Yamaguchi M, Oshima Y, et al. Suppression of the secretion of atrial and brain natriuretic peptide after total cavopulmonary connection. J Thorac Cardiovasc Surg. 2000;120:764-9.

15. Nakazawa M, Marks RA, Isabel-Jones J, Jarmakani JM. Right and left ventricular volume characteristics in children with pulmonary stenosis and intact ventricular septum. Circulation. 1976;53:884-90.

16. Klemola R, Tikkanen I, Vuolteenaho O, Toivonen L, Laine M. Plasma and pericardial fluid natriuretic peptide levels in postinfarction ventricular dysfunction. Eur J Heart Fail. 2001;3:21-6.

17. Bolger AP, Sharma R, Li W, et al. Neurohormonal activation and the chronic heart failure syndrome in adults with congenital heart disease. Circulation. 2002;106:92-9.

18. Maack T, Suzuki M, Almeida FA, et al. Physiological role of silent receptors of atrial natriuretic factor. Science. 1987;238:675-8.

19. Suga S, Nakao K, Hosoda K, et al. Receptor selectivity of natriuretic peptide family, atrial natriuretic peptide, brain natriuretic peptide, and C-type natriuretic peptide. Endocrinology. 1992;130:229-39.

20. Yoshibayashi M, Kamiya T, Saito Y, et al. Plasma brain natriuretic peptide concentrations in healthy children from birth to adolescence: marked and rapid increase after birth. Eur J Endocrinol. 1995;133: 207-9. 